\title{
Temporary Kerato-Prosthesis to Resolve Traumatic Loss of a Healed Corneal Button
}

\author{
Alessandra Balestrazzi ${ }^{a} \quad$ Alessandro Di Maggio $^{b}$ Paolo Michieletto ${ }^{a}$ \\ Gianluca Martone $^{\mathrm{b}} \quad$ Angelo Balestrazzi $^{\mathrm{b}}$

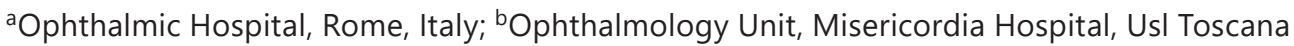 \\ Sud Est, Grosseto, Italy
}

\section{Keywords}

Temporary kerato-prosthesis $\cdot$ Corneal button loss $\cdot$ Trauma

\begin{abstract}
The aim of this study is to report a rare case of traumatic complete loss of a donor corneal button successfully resolved by a 24-h implantation of a temporary kerato-prosthesis. A healthy 30-year-old man with a history of prior penetrating keratoplasty (PKP) presented with an open globe following accidental contusive trauma with a ball, while he was playing football. At slit-lamp evaluation, complete dehiscence of the wound at the graft-host junction and complete corneal button loss was evident. The patient was immediately taken to the operating room, but a donor cornea was not available; therefore, a vitreo-retinal temporary keratoprosthesis was implanted to close the eyeball until a new donor cornea was available. In case of complete dehiscence of the donor-host junction after PKP with corneal button loss, it is possible to use a temporary kerato-prosthesis to stabilize the eye and contain the intraocular structures. We recommend the availability of temporary vitreo-retinal kerato-prosthesis in the operating theatres of Corneal Surgical Units.
\end{abstract}

\section{Introduction}

Wound dehiscence (WD) after contusive trauma is a possible, vision threatening, postoperative complication in patients underwent corneal graft. Keratoplasty is a potential risk factor for globe rupture because it creates a "locus minor resistentiae" for the cornea since the surgical wound never becomes as strength as the normal cornea. Incidence of corneal 
Balestrazzi et al.: Temporary Kerato-Prosthesis Implantation after Traumatic Loss of Corneal Button

WD is not as strong as other post-operative penetrating keratoplasty (PKP) complications and has been reported between 0.6 and $5.8 \%[1,2]$, and it frequently occurs within the first 2 years after surgery. Management of traumatic WD following corneal transplantation could be challenging for the surgeon, especially when a complete loss of the donor button occurred.

Replacing a damaged ad opaque cornea by using an artificial graft is an ancient idea but it became possible only in the 1950s, with the introduction of new materials, such as transparent non-toxic plastics. Nowadays different kerato-prostheses are available, either as definitive solution in complicated leukomas include those that occur due to severe eye-burns, cornea traumas, kerato-uveitis, terminal stages of edematous bullous keratopathy, ocular pemphigoid and trachoma, as well as cases for which multiple corneal graft failures have occurred or human donor corneas are not available for keratoplasty [3], or as temporary solution in vitreo-retinal surgery, for severe ocular trauma with combined anterior and posterior segment damage $[4,5]$ or a better visualization of the vitreous and the retina during pars plana vitrectomy in patients with chronic opacities of the cornea.

\section{Case Report}

A healthy 30-year-old man with a history of prior PKP for hereditary corneal dystrophy performed 12 months before in another institution, presented to our ophthalmological emergency office with an open globe following accidental contusive trauma with a ball, while he was playing football. The double running corneal suture was removed 7 days before the trauma occurrence. At slit-lamp evaluation, complete dehiscence of the wound at the graft-host junction and complete corneal button loss was evident, with partial uveal tissue and vitreous protrusion, and traumatic aphakia. At that time, the donor button was not found.

The patient was provided with comprehensive counselling preoperatively. The patient was then immediately taken to the operating room, but a donor cornea was not available since it was night and the local eye bank was closed. A Wide-Field Landers temporary keratoprosthesis (Ocular Instruments, Bellevue, WA, USA) was then applied after uveal tissue repositioning and anterior vitrectomy. The patient was examined the day after (shown in Fig. 1a, b), and through the temporary kerato-prosthesis, it was possible to partially explore the retina, which appeared adherent as far as it was possible to visualize. The same day a new donor button was available, and we proceeded to remove the temporary kerato-prosthesis and applied a full-thickness corneal graft of $8.50 \mathrm{~mm}$ sutured with 16 detached 10-0 nylon stitches while maintaining a constant 23-gauge pars plana infusion throughout the surgery. Meanwhile, the old corneal graft was found attached to a patient's shoe.
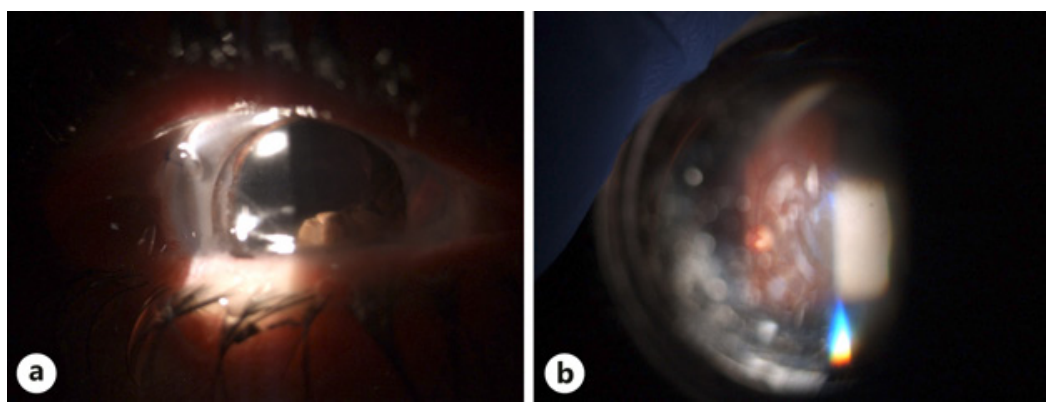

Fig. 1. First post-operative day: anterior segment with implanted kerato-prosthesis (a) and fundus and optic nerve (b).

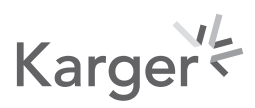


Results

A strict follow-up was performed in the first weeks after the surgery, with slit-lamp and fundus examination, showing good conditions of the corneal flap with rare Descemet folds. An iris coloboma in the nasal sector was evidenced too. Retina was adherent in all the sectors at every follow-up, confirmed by the Ultrasonographic evaluation which did not show evidence of the lens in vitreous chamber.

Visual acuity after 1 month was 20/200 adding +12.0 spherical correction. One year follow-up showed a clear corneal graft (shown in Fig. 2a, b), while visual acuity increased to $20 / 40$ adding +12.5 spherical correction.

\section{Discussion}

Corneal wound healing after keratoplasty is a slow and complex phenomenon. Different studies demonstrated that corneal scar tissue at graft-host interface never regains the same tensile strength as before keratoplasty [6, 7], being decreased by $50 \%$ from a normal cornea, as described by Gassett and Dohlman [8]. The graft-host interface becomes an important point of weakness of the cornea [9]. WD incidence after PKP ranges from 0.6 to 5.8\%, and the most important reason is trauma. Tseng et al. [10] described a possible correlation between WD incidence and age, with older people more affected than younger although Wang et al. [7] did not find a correlation with age. Rehany and Rumelt [11] reported traumatic WD to be more common in younger individuals and especially in those who had undergone keratoplasty for keratoconus. WD after PKP mainly occurs soon after sutures removal, usually within the first 2 years.

WD may be associated with many severe ocular complications including iris prolapse, crystalline or intraocular lens expulsion or dislocation, extrusion of vitreous, choroidal haemorrhage, total disruption of intraocular contents. Patients underwent PKP tended to suffer more severe complications from WD than patients underwent Anterior Lamellar Keratoplasty, which tended to have better final vision acuity and also less extensive wound dehiscence [12].

Different case series described an immediate wound repair, under general anaesthesia, using the original graft, even if the graft appears oedematous and opaque at the time of injury [6]. Topping et al. [13] described 4 cases of traumatic corneal graft dehiscence in which the initial graft was oedematous following trauma, but it slowly underwent deturgescence and regained excellent clarity. Clear corneal graft percentage after traumatic WD was reported to be $20-100 \%$ in several studies $[10,14]$.
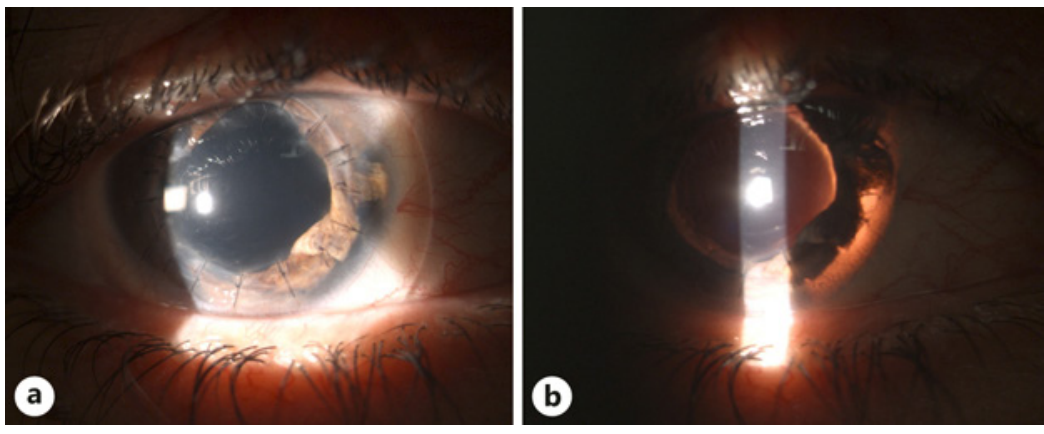

Fig. 2. One year post-operative: corneal button with single stitches (a) and retro-illuminated anterior segment (b).

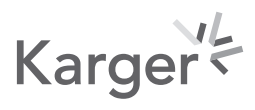


When the WD is complete, and the original graft is not available; a new graft from donor cornea should be implanted. In our case report, the donor button was lost, and a new donor button was not available. It was decided to close the globe using an $8 \mathrm{~mm}$ Landers Temporary Kerato-prosthesis. The protruded uveal tissue was replaced. Temporary kerato-prosthesis is a useful intraoperative tool to visualize the posterior segment in case of corneal opacities such as post-traumatic corneal wounds, and it is usually replaced by a donor corneal graft at the end of pars plana vitrectomy. Our patient maintained the kerato-prosthesis until the next day when a donor cornea was made available.

\section{Conclusions}

In case of complete dehiscence of the donor-host junction after PKP with corneal button loss, it is possible to use a temporary kerato-prosthesis to stabilize the eye and contain the intraocular structures. We recommend the availability of temporary vitreo-retinal keratoprosthesis in the operating theatres of Corneal Surgical Units. After major traumas in PKP eyes, the kerato-prosthesis implantation makes possible a temporary eyeball closure until a new donor button is available.

\section{Statement of Ethics}

This study was carried out in accordance with the Declaration of Helsinki, and the protocol was approved by the Institute Board of each of the two Hospitals. The patient gave his written informed consent to publish his case (including publication of images).

\section{Conflict of Interest Statement}

The authors have no conflicts of interest to declare.

\section{Funding Sources}

No funding was received in relation to the preparation of this case report.

\section{Author Contributions}

Alessandra Balestrazzi: drafting of the manuscript, patient consenting, and surgeon. Alessandro Di Maggio: drafting of the manuscript and literature review. Paolo Michieletto: patient assessment, data collection, and manuscript review. Gianluca Martone: review of the manuscript and provision of specialist knowledge in analysis of the case. Angelo Balestrazzi: drafting of the manuscript, interpretation of significance in the context of the literature review, and corresponding author.

\section{Karger'k}


Balestrazzi et al.: Temporary Kerato-Prosthesis Implantation after Traumatic Loss of Corneal Button

\section{References}

1 Tseng SH, Lin SC, Chen FK. Traumatic wound dehiscence after penetrating keratoplasty: clinical features and outcome in 21 cases. Cornea. 1999;18(5):553-8.

2 Kartal B, Kandemir B, Set T, Kuğu S, Keleş S, Ceylan E, et al. Traumatic wound dehiscence after penetrating keratoplasty. Ulus Travma Acil Cerrahi Derg. 2014 May;20(3):181-8.

3 Iakymenko S. Forty-five years of keratoprosthesis study and application at the Filatov Institute: a retrospective analysis of 1,060 cases. Int J Ophthalmol. 2013 Jun 18;6(3):375-80. Print 2013.

4 Helsen S, Ní Dhubhghaill S, Zakaria N, Koppen C. Eckardt keratoprosthesis for tectonic repair of a large corneal perforation. Cornea. 2016 Aug;35(8):1147-9.

5 Mannis MJ, May DR. Use of the temporary keratoprosthesis in the subacute management of massive ocular trauma. Ann Ophthalmol. 1983 Aug;15(8):773-7.

6 Pettinelli DJ, Starr CE, Stark WJ. Late traumatic corneal wound dehiscence after penetrating keratoplasty. Arch Ophthalmol. 2005 Jun;123(6):853-6. Erratum in: Arch Ophthalmol. 2005 Aug;123(8):1158.

7 Wang X, Liu T, Zhang S, Qi X, Li S, Shi W, et al. Outcomes of wound dehiscence after penetrating keratoplasty and lamellar keratoplasty. J Ophthalmol. 2018 Jul 8;2018:1435389.

8 Gasset AR, Dohlman CH. The tensile strength of corneal wounds. Arch Ophthalmol. 1968 May; 79(5):595-602.

9 Barut Selver Ö, Palamar M, Eğrilmez S, Yağcl A. Traumatic wound dehiscence after penetrating keratoplasty. Ulus Travma Acil Cerrahi Derg. 2016 Sep;22(5):437-40. PubMed PMID: 27849319.

10 Tseng SH, Lin SC, Chen FK. Traumatic wound dehiscence after penetrating keratoplasty: clinical features and outcome in 21 cases. Cornea. 1999 Sep;18(5):553-8.

11 Rehany U, Rumelt S. Ocular trauma following penetrating keratoplasty: incidence, outcome, and postoperative recommendations. Arch Ophthalmol. 1998 Oct;116(10):1282-6.

12 Jafarinasab MR, Feizi S, Esfandiari H, Kheiri B, Feizi M. Traumatic wound dehiscence following corneal transplantation. J Ophthalmic Vis Res. 2012 Jul;7(3):214-8.

13 Topping TM, Stark WJ, Maumenee E, Kenyon KR. Traumatic wound dehiscence following penetrating keratoplasty. Br J Ophthalmol. 1982 Mar;66(3):174-8.

14 Foroutan AR, Gheibi GH, Joshaghani M, Ahadian A, Foroutan P. Traumatic wound dehiscence and lens extrusion after penetrating keratoplasty. Cornea. 2009 Dec;28(10):1097-9. 